facture of home-produced motor spirit by guaranteeing for ten years a preference at the rate of fourpence a gallon in respect of light hydrocarbon oils manufactured in Great Britain from indigenous coal, shale, or peat, or from products derived from these substances. The guarantee period will be subject to certain reductions if the Customs and Excise duties differ by more than the sum stated. $\mathrm{Mr}$. MacDonald estimates that about 7,000 men will be directly, and a slightly smaller number indirectly, employed. The plant which he has in mind will, he stated, be capable of producing about $30,000,000$ gallons of petrol annually, and will consume 350,000 tons of coal a year. Any manufacturer may avail himself of the guarantee, and the petrol may be manufactured by any method from the specified raw materials.

THat such a scheme should be possible with prospect of commercial success and with small cost to the Treasury is a high tribute to the scientific and industrial research which has been applied at no little cost and with well-founded faith in a successful outcome of the experimental work. It is generally stated that the production contemplated is not more than about one-fortieth of the present requirements of Great Britain in motor spirit, but should the undertaking justify further development, this fraction will doubtless be increased, especially if concurrent researches indicate the possibility of further improvements and economies in the process of manufacture. Imperial Chemical Industries Ltd., whose experimental hydrogenation plant at Billingham has given such promising results, are to be congratulated on their enterprise in this field of chemical industry. Sir Harry MeGowan, chairman of Imperial Chemical Industries Ltd., announced on July 18, that in view of the Prime Minister's statement referred to above, the directors have authorised a scheme for the erection of a large commercial plant at Billingham. The capital required, about $£ 2,500,000$, will be provided by the company.

\section{Chemistry and the Textile Industry}

Dr. R. H. Pickard's presidential address to the Society of Chemical Industry, delivered at Newcastleon-Tyne on July 11, on "The Industrial Uses of Textiles" provided a striking illustration of the extent to which the attack on industrial problems is breaking down the division between different classes of scientific workers. Textile research provides a notable example of the extent to which co-operation between the physicist, the chemist, the mathematician, the plant genetist, and the technologist is essential if the problems presented are to be solved. The emphasis laid by Dr. Pickard in this address on the contribution of the physicist, for example, was fully in keeping with the diminishing emphasis which is now being placed on the chemical side in the meetings of the Society of Chemical Industry, and it is undoubtedly true that recent developments of the Society in the formation of such groups as the Food Group and the Plastics
Group have accentuated a definite tendency of the Society to become representative of scientific industry and not chemical industry alone or in the narrower sense.

Dr. Pickard referred in particular to the possibility of quantitative data on the properties of fibres being utilised for the building of fabries more suited to the purpose for which they are intended, and suggested that there is a wide field of investigation to exploit more fully the unique characteristics of textile fabrics. Discussing the ways in which both academic and technical research may aid in developing the more advantageous use of textile fibres for specifie purposes, Dr. Pickard referred to the possibilities of the new technique of electron diffraction, the little-used technique of molecular rays. With a general revival of trade, there may arise an all-round demand by industry for welltrained chemists whose technique is not limited to that required in investigations of atomic structure.

\section{Chemistry of Combustion}

Prof. W. A. Bone's address, "Forty Years of Combustion Research", delivered on July 12 on the occasion of the presentation of the medal of the Society of Chemical Industry, was a brilliant review of experimental research in this field, and the clarity of its delivery no less than the lucidity and felicity of exposition which characterised it made the occasion one which will be long remembered by those present. A skilful picture of the position unfolded by Dixon in his lectures at Owen's College, Manchester, when $\mathrm{Br}^{-}$. Zentered the College in 1888, was followed by an account of the development of the theories of detonation, down to the development of the new technique for the investigation of 'spin' in detonation which enables us to measure with precision periodic flame movements occurring with frequencies up to a million a second. Discussing research on the combustion of hydrocarbons, Prof. Bone referred to the recent quantitative proof of the 'hydroxylation' theory, suggested by H. E. Armstrong in 1874, offered by D. M. Newitt and A. M. Bloch's recent pressure-oxidation experiments on ethane and acetylene. Surface combustion, ignition phenomena and initial flame movements were touched upon in the same masterly manner, and a brief review given of the results obtained in gaseous combustion at high pressure, leading to the discovery of 'nitrogen activation' in carbon monoxide-air explosions, with the investigation of which Prof. Bone commenced his researches. Direct and cumulative evidence, chemical and spectrographic, all appears to lead to the conclusion that carbon monoxide can burn in two ways, directly, without any intervention of steam, and indirectly, either through steam or as a result of its intervention, pressure favouring the former. In concluding, Prof. Bone emphasised the need for the elaboration of an adequate technique, and the dependence of progress on accurate and completely analytical operations under experienced guidance. 